\title{
La funcional interrelación epistemológica e ideológica entre filosofía, ética y política ${ }^{26}$
}

A la filosofía, al igual que a la ética y la política se le pueden atribuir múltiples funciones, analizadas anteriormente, que explican por qué tantos seres humanos en distintas épocas y circunstancias se han dedicado a su cultivo.

Múltiples culturas, antes y al margen de la occidental, han elaborado profundas y originales ideas políticas, jurídicas y éticas sobre el ser humano, sus derechos y formas de organización política, en particular las democráticas (Guadarrama, 2009b, pp. 79-96)

Las funciones lógico-metodológica, axiológica, hegemónica, práctico-educativa, emancipadora, ética y estética de la filosofía, en cierta forma han estado subsumidas en la función axiológica y articuladas con la ideológica, si se entiende esta última no como falsa conciencia o simple imagen pretensiosa de la realidad social, sino como conjunto de ideas que conforman la concepción de una clase o grupo social y están dirigidas al sostenimiento o realización de su poder respecto a toda la sociedad, o al menos en nombre de ellas.

26 Publicado en Ángel Álvarez, Jaime Alberto. Aportes para una filosofía del Sujeto, el Derecho y el Poder. Universidad Libre de Colombia. Bogotá. 2012, pp. 221-264. 
Tanto a la filosofía como a la ideología y hasta la política le han celebrado múltiples entierros prematuros, en algunos casos preconizando de forma ilusoria una futura hegemonía de la moral sobre estas. Sin embargo, todas ellas se resisten a desaparecer sin antes haber cumplido sus respectivas funciones vitales.

La función ideológica, al igual que la epistemológica, acompañarán al ser humano en tanto éste sea generador de proyectos de organización y perfeccionamiento social, para lo cual resulta imprescindible enriquecer sus potencialidades. Y, por suerte, parece que la inconformidad con los regímenes socioeconómicos y políticos, incluidos los presentes, constituye una constante de la condición humana.

El día que hipotéticamente desaparezca el afán del género humano por explicar de manera racional las causas que impulsan a los fenómenos naturales y sociales y la manera de encaminarlos mejor en provecho del humano, entonces podrá admitirse que languidecerán la filosofía y la ideología, y en ese caso la ética y la política no tendrían mucha razón de ser. Mientras tanto, todas ellas tienen aún mucho que hacer. De lo contrario, habría que pensar que nuestra actual estructura mental no está capacitada para disfrutar de las "ventajas" y posibilidades del nihilismo.

Generaciones anteriores tampoco tuvieron dicha capacidad. Algunas más antiguas ni siquiera se percataron del todo que filosofaban con culpabilidad ideológica, en su afán con cumplir con intereses epistemológicos. Lógicamente, el hecho de que no tomaran conciencia del componente ideológico de sus reflexiones, no significa en modo alguno que este estuviese ausente en ellas.

El término ideología fue creado a principios del siglo xix por Destutt de Tracy quien lo consideraba una parte de la zoología que trata sobre la formación de las ideas (Tracy, 1824, p. 285). A su juicio los precursores de esta "ciencia" eran Condillac y Locke.

El hecho de que la ideología haya sido concebida originalmente por su padrino como una ciencia del mismo modo y por la misma época en que Comte bautizaba el término de sociología como ciencia de la sociedad, resulta, sin dudas de interés y evidencia la intención de optimismo epistemológico que embargaba a ambos pensadores franceses. Especialmente si se tiene en consideración que esta última demoró mucho en alcanzar el debido reconocimiento por parte de la comunidad científica, en tanto 
la ideología no solo no lo ha logrado hasta el presente, sino que mantiene aún su anatema de anticientífica.

Filósofos de otras épocas se habían percatado de la indiscutible proclividad al error latente en el pensamiento humano cuando se trata de la gestación y consolidación de nuevas ideas. Siempre existe la posibilidad de sostener como válidos múltiples juicios cuyo carácter insostenible la historia luego se encarga de revelar.

Sin embargo, en ocasiones demora mucho tiempo en que se demuestre la falsedad de determinadas concepciones. Aparentemente, o incluso realmente, pueden operar algunos fenómenos en armoniosa correspondencia con determinadas tesis, en última instancia falsas, que se sostienen durante un tiempo y en ese período gozan de merecido prestigio.

La humanidad parece tardar milenios en superar formas alienantes de su poder, como las que generan el oscurantismo y otras ideas religiosas, especialmente los fundamentalismos, que se presentan como verdades supremas e indiscutibles. Tal es el grado de alienación predominante que da lugar a que aquellos que logran sobreponerse a tales engaños aparezcan ante las mayorías creyentes como seres anormales o carentes de la cualidad de lo humano. El poder de las ideologías es significativo cuando se empeñan en tergiversar o entorpecer el conocimiento de las relaciones realmente existentes entre los humanos, así como entre estos y la naturaleza.

Entre los filósofos que prestaron temprana atención a las causas de la generación de juicios falsos se destacó Francis Bacon (1963). Según él, "el espíritu humano (tal como se dispone en cada uno de los hombres), es una cosa variable, sujeta a toda clase de perturbaciones y casi a merced del momento" (p. 16).

Ese carácter circunstancial del error fue muy tomado en consideración por otros pensadores como Helvecio, quien aseguraba que no solo la ignorancia, sino también las pasiones, inducen a error porque hacen fijar toda nuestra atención sobre una parte del objeto que nos presentan y no nos permiten considerarlo en su totalidad (Helvetius, 1973, p. 27). Esto no significa que el ser humano por naturaleza esté condenado al error, sino que condiciones accidentales como la ignorancia o las pasiones le hacen caer en él.

El materialismo francés del siglo xviII, y en especial el de Holbach, fue lo suficientemente sagaz para descubrir que los errores y prejuicios humanos 
no son ni el producto de una maldición divina, ni una distorsión de la naturaleza (Holbach, 1989, p. 223). ${ }^{27}$

La toma de plena conciencia del componente ideológico en el discurso filosófico constituye, en verdad, un producto de la modernidad. Pero desde la antigüedad el factor ideológico ha desempeñado sus funciones en interrelación con el epistemológico en toda producción de ideas filosóficas, y muy especialmente en el terreno de la ética y la política.

Al enunciar la diferencia entre ciencia y opinión, Platón planteaba de hecho la necesidad de prestar atención a la diferencia entre creencias verdaderas y falsas en el siguiente diálogo:

Sócrates: -Piensas bien, y de ello te daré una prueba. Si te dijese: Gorgias, hay una creencia falsa y una verdadera; sin dudas convendrías en ello.

Gorgias. - Sí

Sócrates. - ¿Pero hay también una ciencia falsa y una ciencia verdadera? Gorgias. - No, ciertamente.

Sócrates. - Luego es evidente que saber y creer no son la misma cosa. Gorgias. - Es cierto.

Sócrates. - Sin embargo, los que saben están persuadidos lo mismo que los que creen.

Gorgias. - Convengo en ello.

Sócrates. $-\dot{i}$ Quieres por consiguiente que admitamos dos clases de persuasión: una que produce la creencia sin la ciencia, y otra que produce la ciencia?

Gorgias. - Sin duda.

Sócrates.- De estas dos persuasiones, ¿cuál es la que la Retórica produce en los tribunales y en las demás asambleas, a propósito de lo justo y lo injusto? ¿Aquella de la que nace la creencia sin la ciencia, o la que engendra la ciencia?

Gorgias.- Es evidente, Sócrates, que es aquella de que nace la creencia. (Platón, 1946, p.464).

27 "Nunca se repetirá bastante, que la verdadera causa de todos los males que afligen a la raza humana es debida al error, y de ningún modo a la naturaleza; no es un Dios irritado que quiso que viviese en la amargura, ni una depravación hereditaria la que ha hecha a los mortales malos y desgraciados, sino únicamente el error, a quien solo se deben atribuir todos esos deplorables efectos". Holbach, P. H. Sistema de la naturaleza. Editorial Ciencias Sociales. La Habana. 1989. p. 223. 
Podríamos añadir también la ideología, cuyo criterio de aceptación de una idea ha sido por lo regular no tanto su condición de verdadera como de justa.

La ciencia, por su parte, desde sus albores, ha presumido de aceptar solamente las creencias verdaderas, con independencia de su justeza o no, aunque sobran ejemplos que demuestran que no siempre ha procedido de tal modo. Es posible coincidir con Popper en que "Los científicos individuales tienen incluso algo así como una justificación metodológica para ser dogmáticos y tener prejuicios" (Popper, 1997, p.87) ${ }^{28}$ Los trascendentales cambios que se produjeron con el desarrollo de la física quántica evidenciaron lo limitado que resultaban algunos de los principios newtonianos aceptados durante mucho tiempo como absolutamente verdaderos, sin tomar en debida consideración que en la ciencia la única verdad absoluta que es válida es que no existen verdades absolutas.

Desde la antigüedad los filósofos han mantenido una preocupación constante por lograr la adecuada articulación entre los criterios de verdad, justicia y virtud, así como los mecanismos a través de los cuales éstas se expresan en la opinión pública. Por supuesto que durante el medioevo no se mantendrían las mismas inquietudes al "resolver" de forma muy sencilla la cuestión, pues ambas, verdad y justicia, estaban contenidas y reveladas en Dios.

Pero la crítica modernidad que puso en tela de juicio todos los órdenes y concepciones existentes acentuaría su atención sobre el asunto y tal actitud le conduciría a tener que afrontar el problema del componente ideológico en la filosofía con mayor interés.

Por ideología se debe entender el conjunto de ideas que pueden constituirse en creencias, valoraciones y opiniones comúnmente aceptadas y que articuladas integralmente pretenden fundamentar las concepciones teóricas de algún sujeto social — clase, grupo, Estado, país, iglesia, entre otras-, con el objetivo de validar algún proyecto, bien de permanencia o de subversión

28 "Puesto que el método de la ciencia es el de la discusión crítica, es enormemente importante que las teorías criticadas sean defendidas con tesón. Pues sólo de esta manera podremos conocer su poder real. Y sólo si la crítica encuentra resistencia podremos apreciar toda la fuerza del argumento crítico". Popper, Karl. El mito del marco común. En defensa de la ciencia y la racionalidad. Paidos Básica. Barcelona. 1997. p. 87. 
de un orden socioeconómico y político, lo cual presupone a la vez una determinada actitud ética ante la relación humano-humano y humano-naturaleza.

Para lograr ese objetivo puede o no apoyarse en pilares científicos, en tanto estos contribuyan a los fines perseguidos, de lo contrario es posible que sean desatendidos e incluso ocultados conscientemente. Según Frederic Jameson (1999) "la palabra ideología no es peyorativa (...) un concepto puede ser al mismo tiempo ideológico y también correcto y verdadero" (p.76).

El componente ideológico en las reflexiones filosóficas por sí mismo no es dado a estimular concepciones científicas, pero tampoco esto significa que excluya la posibilidad de la confluencia con ellas en tanto estas contribuyan a la validación de sus propuestas.

"Lo que hace de la ideología una creencia — plantea Abbagnano (1966)— No es, en efecto, su validez o falta de validez, sino solo su capacidad de control de los comportamientos en una situación determinada." (p. 646).

Uno de los rasgos distintivos de aquellas formulaciones que son caracterizadas como ideológicas ha sido la posibilidad de ser manipuladas en cualquier sentido y la facilidad de adaptación a los mecanismos de argumentación que impone algún tipo de poder en lugar del adecuado poder de la argumentación lógica.

Si bien el componente ideológico ha estado y estará siempre presente en toda filosofía, del mismo modo que en toda ética y política, lógicamente su incidencia en estas últimas ha sido y será mucho mayor, a la vez que más explícita que en la primera, dada la presunta preeminencia del componente epistemológico que acompaña a toda filosofía. Sin embargo, la activa interconexión entre la filosofía y la política que ha hecho decir a Althusser "todo lo que atañe a la política puede ser mortal para la filosofía, ya que esta vive de ella"(Althuseer, 1969, p. 125), obliga a no desatender la significación de lo ideológico y lo ético en la escrutadora mirada del Búho de Minerva.

El componente ideológico no es una mera invención o absolutamente una expresión de "falsa conciencia", aunque en determinados momentos realmente pueda serlo.

La ideología puede comportarse en determinadas circunstancias como falsa conciencia o imagen invertida de la realidad, como la concibieron en 
sus trabajos tempranos Marx y Engels (1965b, p. 25). ${ }^{29}$ Pero eso no significa que en todo momento lo sea. Siempre hay que tomar precaución sobre la posibilidad de deslizarse hacia bizantinas discusiones "marxistas" sobre este concepto, si se toma en consideración que, como plantea Eugenio Trías, "Marx nunca elaboró esa teoría; ni siquiera definió el término 'ideología' con rigor" (Trías, 1975, p. 5). Esto no significa, por supuesto, que entonces no deba abordarse la cuestión con la profundidad que merece en la evolución de lo que reconoce como el marxismo, pero siempre precavidos de no reclamar privilegiadas posiciones de interpretación exclusiva como han proclamado ciertos autoproclamados "marxismos".

Marx y Engels utilizaron inicialmente el término ideología en el sentido usual por entonces, cargado de significación peyorativa desde la visión napoleónica, y resulta inadecuado pasar por alto el contexto específico en el cual ellos formularon tal criterio. Y sí destacaron que el fenómeno de la ideología responde a su proceso histórico de vida. Lógicamente, si es histórico, no puede ser siempre idéntico. Por tanto, las relaciones y fenómenos que se deriven de tal proceso histórico - entre ellos los ideológicos - tienen necesariamente que ser diferentes y evolucionar.

Ante todo, en ese análisis se estaban refiriendo, como anteriormente apuntaban, a la "producción de las ideas y representaciones, de la conciencia”, es decir, a lo que de Tracy concebía como el contenido de su pretendida ciencia, la cual lógicamente encontraría en el materialismo filosófico de Marx y Engels el acostumbrado enfrentamiento crítico a todo lo que oliese a especulación y al usual "lenguaje de la política, de las leyes, de la moral de la religión, de la metafísica, etc., de un pueblo” (Trías, 1975, p. 5), que también en nuestros días generalmente dista mucho de la realidad.

Resulta obvio pensar que Marx y Engels estaban tomando distancia de las carcomidas formas de construir sistemas filosóficos, éticos y, sobre todo, políticos, ocultos siempre en un embrollado discurso tan etéreo como falso. En tal sentido, aseguraban que:

29 "La conciencia no puede ser nunca otra cosa que el ser consciente, y el ser de los hombres es su proceso de vida real. Y si en toda la ideología los hombres y sus relaciones aparecen invertidos como en la cámara oscura, este fenómeno responde a su proceso histórico de vida, como la inversión de los objetos al proyectarse sobre la retina responde a su proceso de vida directamente físico". Marx, C. y F. Engels. La ideología alemana. Editora Revolucionaria. La Habana. 1965. p. 25 
La moral, la religión, la metafísica y cualquier otra ideología, y las formas de conciencia que a ellas corresponden pierden, así, la apariencia de su propia sustantividad. No tienen su propia historia ni su propio desarrollo, sino que los hombres que desarrollan su producción material y su intercambio material cambian también al cambiar esta realidad, su pensamiento y los productos de su pensamiento. No es la conciencia la que determina la vida, sino la vida la que determina la conciencia. (Marx, C. y F. Engels. La ideología alemana. Editora Revolucionaria. La Habana. 1965.p. 26).

Su mayor interés era en este caso acentuar la postura materialista en el plano ontológico y gnoseológico de la cuestión de la génesis, en última instancia, de las ideas. Su pretensión no era convertirse en sepultureros precoces de toda historia de la filosofía, de la religión, las ideas políticas, jurídicas, y otras.

Era lógica aquella aseveración si se refería a la forma propiamente especulativa, abstracta y alejada de la realidad que ha sido común a tantos sistemas de ideas éticas, religiosas o filosóficas. A este tipo de sistemas se referían, a nuestro juicio Marx y Engels, al negarles "su propia sustantividad".

De otro modo resultaría ingenuo sostener que Marx y Engels negaron propiamente la existencia de la historia de la filosofía, de la religión, de las ideas éticas, políticas, jurídicas y demás, cuando existen múltiples pruebas no solo del reconocimiento de su existencia, sino de estimular su cultivo. Como en el caso de la recomendación engelsiana (Engels, 1961, p. 23) ${ }^{30}$ de estudiar la historia de la filosofía como vía para ejercitar el pensamiento.

Los mejores deseos de Marx y Engels estaban dirigidos a que se pusiera fin a la falseada modalidad de construir ideologías, filosofías y sistemas éticos apriorísticos, como se pudo apreciar en algunas interpretaciones del marxismo-leninismo, configurado en época de Stalin con fines eminentemente ideológicos para tratar de justificar una determinada práctica política, social, científica, cultural y especialmente filosófica, que fosilizó el

30 "Ahora bien, el pensamiento teórico solo es un don natural en lo que a la capacidad se refiere. Esta capacidad tiene que ser cultivada y desarrollada; y hasta hoy, no existe otro medio para su cultivo y desarrollo que el estudio de la historia de la filosofía". Engels, Federico. Dialéctica de la naturaleza. Editorial Grijalbo. México. 1961. p.23. 
materialismo histórico y lo convirtió, junto al engendro del materialismo dialéctico, en una teoría especulativa, abstracta y alejada de la realidad. Ello motivó a que Ernesto (Che) Guevara lo caracterizara como una nueva escolástica (Guadarrama, 2005a, pp. 40-47). La realidad es testaruda y no siempre coincide con las aspiraciones de los más talentosos científicos o pensadores, por bien intencionadas que estas sean.

La valentía académica de muchos de los marxistas ha sido la denuncia del fermento tergiversador que encierra lo ideológico, que como poderoso bumerán puede y ha tenido que ser aplicado también a las ideas y a la práctica de los propios marxistas.

Pero presuponer que toda formulación ideológica proveniente de cualquier pensador porta fatalmente la carga culpable de la falsedad, implicaría la contraproducente conclusión de la imposibilidad de escapar de las redes del engaño cuando de ideología se trate.

Si Marx y Engels hubiesen pensado siempre así, no hubiesen tenido incluso la menor muestra de autoestimación de la labor política e ideológica que desarrollaban. Aun cuando sus intenciones y la mayor parte de su actividad intelectual poseían un carácter científico, - reconocido hasta por intelectuales de derecha como en el caso de Raymond Aron en su homenaje a Marx en la UNESCO con motivo del centenario de su muerte- no es sostenible pensar que ignorasen la carga ideológica de su obra. En verdad, en ella nunca estuvo distanciado el componente científico del ideológico ni de la exigida fundamentación ética.

Lo mismo se haría extensivo a otros marxistas, y entre ellos a Lenin, quien encontró una solución superadora de la trampa que presuponía considerar la ideología solamente en sentido negativo, por lo que diferenció claramente cuándo una ideología se comporta como falsa y como verdadera (Lenin, 1963a, p. 262) a partir de la condicionalidad histórica de ellas. Esto posibilita, a su juicio, la existencia de una "ideología científica" (Lenin, 1963b, p. 135) que nada tiene que ver con otras formas ideológicas, como la religiosa. Por ese motivo planteó:

Pero el socialismo que es la ideología de la lucha de clases del proletariado, se halla sujeto a la condición general del nacimiento, el desarrollo y la consolidación de toda ideología; es decir, descansa sobre todo el material de los conocimientos humanos, presupone 
un alto desarrollo de la ciencia, requiere una labor científica, etc., etc. Son los ideólogos los que introducen el socialismo en la lucha de clases del proletariado, que se desarrolla espontáneamente sobre la base de las relaciones capitalistas. (Lenin, 1959c, p. 161).

Idea esta que anteriormente había sido formulada por Kautsky (Sánchez, 1982, p. 34) y con la cual Lenin coincidió.

Esta concepción dista mucho de la consideración de toda ideología como falsa conciencia. Es una concepción diferenciadora no solo de la existencia de una ideología burguesa caracterizada por una serie de libertades de pensamiento, prensa, palabra, culto, entre otras (Lenin, 1959c, 262), frente a una ideología proletaria fundada en lo que se denominaba el socialismo científico, es decir, el marxismo (Lenin, 1959c.p. 346), que no consideró como exclusiva portadora del progreso social.

Lenin llegó a diferenciar entre ideología burguesa progresista e ideología burguesa reaccionaria (Lenin, 1959d, p.445). Todo lo cual indica que utilizó el concepto de ideología de forma histórico concreta. Esto le permitió encontrarle nuevas determinaciones al concepto y en especial plantear su posible articulación con los resultados de la investigación científica.

Para algunos marxistas, como el venezolano Núñez Tenorio "la oposición ideología-ciencia está en la base misma (ideológico-crítica) del marxismo" (Núñez, 1976, p.360). Este criterio parte del equívoco presupuesto de que Marx y Engels siguieron siempre considerando la ideología como falsa conciencia, tal como la concibieron en sus trabajos tempranos.

El análisis de sus obras posteriores demuestra que, aunque profundizaron en fenómenos coincidentes en su forma, como el componente ideológico en el fetichismo de la mercancía, resulta extrapoladora la búsqueda de cierta "plusvalía ideológica" (Silva, 1984, p.190), ${ }^{31}$ en sus obras de madurez.

31 "Muy a grandes rasgos nuestra hipótesis consistiría en preguntarnos si es posible , teniendo en cuenta la afirmación de Marx de que las relaciones de producción se reproducen en el plano de la ideología, pensar que, así como en el taller de la producción material capitalista se produce como ingrediente específico la plusvalía, así también en el taller de la producción espiritual dentro del capitalismo se produce una plusvalía ideológica, cuya finalidad es la de fortalecer y enriquecer el capital ideológico del capitalismo; capital que, a su vez, tiene como finalidad proteger y preservar el capital material". Silva, L. La plusvalía ideológica. Universidad Central de Venezuela. Caracas. 1984. p. 190. 
Aun cuando en el capitalismo la ideología burguesa tiene como fin el sostenimiento de esa sociedad, esta función no es inherente a toda ideología y mucho menos a la revolucionaria que genera esa sociedad.

Mantener el criterio de la ideología como falsa conciencia significa ignorar la evolución que tuvo este concepto en el seno del marxismo, como se pudo apreciar anteriormente en el caso de Lenin, así como en Gramsci, quien también supo diferenciar las ideologías (Gramsci, 1966, p. 58), ${ }^{32}$ al igual que otros marxistas. Esa es la posición de Ludovico Silva, quien decidió asumir el concepto de ideología en el exclusivo sentido en que lo manejó Marx. Según él, "Sobre la ideología, me incitan a precisar más mi propia visión del problema. Yo insistía en que se deben tomar en cuenta, para comprender lo fundamental de toda ideología, los aspectos no conscientes de la misma, dejando, como hacía Marx, la conciencia para cosas contrapuestas a la ideología, como la teoría y la ciencia; pero esto me llevó a calificar de contradictorias y absurdas, desde el punto de vista de Marx, expresiones leninistas tales como 'ideología revolucionaria', o 'el marxismo como ideología revolucionaria', o 'el marxismo como ideología de la clase obrera’ o la célebre 'toma de conciencia ideológica"' (Silva, 1977, p. 13).

Algunos estudios sobre el tratamiento de la cuestión de la ideología en Marx, Engels y Lenin en los países del llamado "socialismo real", llegaron a plantear la evolución que se operó en aquellos pensadores respecto a la cuestión de la ideología (Buhr, 1970, p. 507). Sin embargo, la limitación dogmática mayor consistió en admitir que la posibilidad de contenidos científicos en el discurso filosófico era exclusiva de la "ideología proletaria”. Al extrapolar la caracterización de falsa conciencia a toda formulación ideológica proveniente del pensamiento burgués echaron por tierra

32 "Es preciso, entonces, distinguir entre ideologías históricamente orgánicas, es decir, que son necesarias a determinada estructura, e ideologías arbitrarias, racionalistas, "queridas". En cuanto históricamente necesarias, estas tienen una validez que es validez "psicológica"; "organizan" las masas humanas, forman el terreno en medio del cual se mueven los hombres, adquieren conciencia de su posición, luchan, etc. En cuanto "arbitrarias, no crean más que movimientos individuales, polémicas, etc. (tampoco son completamente inútiles, porque son como el error que se contrapone a la verdad y la afirma)". Gramsci, Antonio. El materialismo histórico y la filosofía de Benedetto Croce. Ediciones Revolucionaria. La Habana. 1966. p. 58. 
las propias indicaciones de Engels y Lenin dirigidas a justipreciar los núcleos racionales contenidos en el pensamiento burgués.

Algunas interpretaciones del llamado "marxismo occidental" (Merquior, 1987) y otros representantes "heterodoxos" reconocieron que es absurdo plantear la existencia de una "ciencia burguesa" frente a una "ciencia proletaria" (Dion, 1975, p.47), aunque exista, por supuesto una ideología burguesa y otra proletaria.

Los marxistas, en sentido general, han actuado con plena conciencia del componente ideológico, político y moral de sus concepciones, y por tanto, de su práctica. Por tal razón, no han considerado ni que algunas de las verdades en las que asientan sus ideas por ser científicas están descontaminadas del componente ideológico, utópico concreto, diría Ernst Bloch, diferenciándolo del utopismo abstracto e imposible de realizar —ni que por identificarse abiertamente con determinadas posiciones ideológicas su actuación se encuentre alejada de la ciencia y de la verdad.

Hasta los críticos del marxismo como Ramón Vargas-Machuca se ven obligados a reconocer que "lo que en la actualidad podemos retener del marxismo es, en primer lugar, la dimensión ética de su utopismo" (Machuca, 1992, p. 222), y pues para este autor "La moral es, insistía Marx, contextualizada y toma cuerpo en las instituciones políticas y económicas. Restauraba de este modo el marxismo los fueros de la historia en los dominios de la epistemología y de la ética, recordando la parcialidad y relatividad de cualquier punto de vista moral" (Machuca, 1992, p-222).

Tampoco es creíble que Max Weber (Weber, 1959, p. 181)33 o Talcott Parsons hayan considerado que sus ideas han sido exclusivamente científicas y, por tanto, desprovistas de la más mínima carga ideológica. Francis Fukuyama, con honestidad, ha sostenido que si no existieran las condiciones miserables de existencia de grandes sectores sociales en los países atrasados, los marxistas no tendrían razón de ser. Por supuesto que tendría plena consciencia de la enorme responsabilidad ideológica de tal planteamiento. De

33 Cuando Max Weber denunciaba que "en la práctica entre nosotros la carrera científica está edificada en definitiva sobre supuestos plutocráticos, pues es sumamente arriesgado para un científico joven sin bienes de fortuna personal exponerse a los azares de profesión académica", estaba muy consciente de la carga ideológica de su planteamiento. Weber, Max. El político y el científico. Alianza Editorial. 1959. p. 181. 
todo lo anterior se desprende que la funcional interrelación epistemológica e ideológica entre filosofía, ética y política no es profundamente contradictoria en el mejor sentido de la perspectiva dialéctica.

La diferencia estriba en que los marxistas han denunciado la manipulación que es común cuando se incursiona en el terreno de la ideología, sin necesariamente pensar que siempre que se actúe desde una perspectiva ideológica, se discurre por los terrenos de la falsedad. Tampoco es sostenible lo absolutamente contrario, o sea, que cuando se transita por los laberintos de la ciencia, en particular de las ciencias políticas o jurídicas, y mucho menos en el terreno de la ética, se está protegido de las posibles afectaciones de las visiones ideológicas.

La culpabilidad ideológica de los marxistas ha consistido en que no han ocultado sus intenciones de subvertir la sociedad capitalista en aras de beneficiar a las clases sociales mayoritarias, entendiendo que representan un interés de un contenido más universal que los ideólogos de la burguesía. Otra cuestión es que no siempre lo han logrado (Carpentier, 2007, p. 8), ${ }^{34}$ y algunos experimentos de construcción socialista han fracasado en tanto otros se mantienen, con independencia de los presuntos jueces que creen poseer socialistómetros perfectos para pronosticar las soluciones a las antinómicas crisis del socialismo (Guadarrama, 1998). También el capitalismo ha tenido y tiene sus crisis, ensayos exitosos así como fracasados. Las disputas y componendas entre demócratas y republicanos para superar la crisis de la economía del país más endeudado del mundo, especialmente a partir del 2008, así lo atestiguan.

La tradición del pensamiento socialista y lo que se ha dado en llamar marxista, - algo muy contrario a lo que el propio Marx quiso al no desear ser calificado como tal一, no ha ocultado su intención de hacer desaparecer al capitalismo, la burguesía, a los terratenientes y a cualquier manifestación de poder económico enajenante que engendre explotación del "hombre por el hombre", y no solo por una cuestión política o económica, como plantea

34 "En muchos países las ideologías no progresaron eficazmente a causa de la mediocridad intelectual o de la incapacidad organizativa de quienes trataron de inculcarla a las masas". Lo cual no significa necesariamente que ellas en si fuesen falsas o destinadas, sino que su implementación fue la que resultaría errónea”. Carpentier. A. "Problemática de la actual novela latinoamericana" en Carpentier, Alejo. Los pasos recobrados. Ediciones Unión. La Habana. 2007. p. 8 
Maximilen Rubel (1974, p. 33$)^{35}$ sino también eminentemente ética. Por supuesto que tal desaparición se refiere como clase o poder y no a su eliminación como individuos. La franqueza del discurso socialista y marxista, en particular en América Latina (Guadarrama, 1990), en este aspecto ha sido su principal fortaleza ideológica, en tanto que para los que se oponen a estas intenciones esta ha sido su mayor debilidad.

Por el contrario, los defensores del liberalismo o del neoliberalismo en la actualidad, entre otros, por lo regular se asumen como representantes de los intereses de toda la sociedad, sin excluir a ninguna clase o grupo social menos favorecido, que lógicamente no pretenden extinguir, sino reproducir permanentemente, como condición básica de su propio bienestar. Es difícil imaginar la posibilidad de una sociedad solo de burgueses, sin obreros, campesinos, domésticas, empleados de servicio, entre otros.

Las anunciadas fórmulas políticas que presumen encontrar una solución eterna y total a los males sociales semejan a esos medicamentos que se anuncian como curadores de todas las enfermedades posibles, y por eso mismo no sirven para ninguna. Cuando Feuerbach le expresó a Marx que deseaba elaborar una ética para todos los tiempos y todas las circunstancias, este último le respondió que precisamente por eso no serviría para ninguna época ni para ninguna circunstancia, pues no es posible concebir una ética, al igual que la política, que sea válida para todas las épocas y situaciones.

Sin embargo, este hecho no significa demeritar esfuerzos como los de Adela Cortina por crear una ética de la razón cordial con pretensiones de gestar "una ética cívica transnacional" (Cortina, 2007, p. 30), sin que esto signifique que intente evadir el imprescindible fermento de lo ideológico, especialmente de la significación de la dependencia política en relación con la dependencia económica. Por eso la filósofa española reclama "Ser su propio señor en lo político cuando se es vasallo en lo económico, es, en realidad, imposible Y sin embargo el olvido de la dimensión económica es constante en quienes trabajan en la filosofía política" (Cortina, 2007, p. 30).

Algo similar le sucede a Fernando Sabater cuando se plantea un "proyecto de ética universalista, de ética sin fronteras, de ética de la acogida de

35 "Marx concibe el advenimiento del socialismo a la vez como una posibilidad económica y una necesidad ética". Rubel, Maximilien. Páginas escogidas de Marx para una ética socialista. Amorrortu Editores. Buenos Aires. 1974. p. 33. 
lo distinto y de la recepción de lo extranjero que nos revele nuestra humanidad al mostrarnos en la apariencia de lo distinto, lo fundamental que nos une a unos y otros, lo común, que está siendo quizás maltratada o anegada por un diferencialismo extremo, que en nuestro siglo ha llevado a dramas de particular importancia política, histórica, a persecuciones, exclusiones, aniquilamientos masivos" (Sabater, 1999, p. 604). También es la intención de Guilles Lipovesky con su ética universalista laica que pretende articular a lo que él considera un "código genético de las democracias modernas" (Sabater, 1999, p. 605).

Las tres posturas anteriores de pretensión de construcción de éticas universales revelan a flor de piel la articulación entre sus ideas éticas y sus respectivas posturas ideológicas, que a su vez no se distancian del componente epistemológico, sino que se imbrican con él adecuadamente.

Mucho más pertinente resulta la construcción de una moral desde una perspectiva social concreta como la planteada por el filósofo argentino Arturo Andrés Roig (2002) cuando planteaba que "La moral de la emergencia que ha de ser reconstruida a partir de sus variadas manifestaciones provenientes de diversos sectores oprimidos [...] ni requiere tan solo de una hermenéutica, sino que la misma deberá ser planteada como una hermenéutica crítica" (p.79). Esto quiere decir que necesariamente porta una determinada carga ideológica a favor de determinados grupos sociales.

Una concepción de la ética, de la política y de la filosofía desde una posición de compromiso ideológico no tiene necesariamente que afectar el componente epistemológico, pues al igual que en el terreno de la ciencia siempre habrá necesidad de estar muy al tanto de la bachelardiana vigilancia epistemológica, si se aspira a que mantenga credibilidad (Núñez, 2004, p. 64). ${ }^{36}$

Por su parte, los ideólogos neoliberales que aspiran a eternizar el capitalismo saben que mejorando en algo las condiciones de vida de los más desposeídos en los países desarrollados, a expensas de la riqueza de los más atrasados, se evita la explosividad social. Por tal motivo, su discurso

36 "Las prácticas científicas y educacionales siempre se relacionan con ideales epistémicos, por tanto ellas requieren de una permanente "vigilia epistemológica". Nuñez Jover, Jorge. "La ciencia en el encuentro entre ética y epistemología". En Por una nueva ética. Colectivo de autores. López Bombino, Luis. Compilador. Editorial Félix Varela. La Habana. 2004. p. 64. 
ideológico y político se ha hecho más solapado, sutil y teledirigido. A la vez, su discurso ha ido enriqueciéndose epistemológicamente, pues de lo contrario, perdería con rapidez credibilidad.

En cambio, el discurso irracionalista, fascista o fundamentalista es mucho más abierto, incluso más honesto, para plantear también su culpabilidad ética e ideológica, pero de otro género, cuando se aspira a la consagración política del poder de unos "elegidos", bien sea una elite, una raza, un pueblo, una religión, entre otros. En tal sentido, encuentran lógica repulsa tanto de marxistas como de liberales, conscientes todos de las razones por las cuales no es prudente elogiar su singular franqueza ideológica y política.

El hecho de que la práctica del "socialismo real" supuestamente fundamentada en el marxismo haya engendrado nuevas elites burocráticas en el poder, que limitaron la realizaciones de la libertad individual (Bobbio, 1988, p. 66), ${ }^{37}$ ha contribuido a desvirtuar en gran medida las pretensiones ideológicas tanto del discurso socialista auténtico - tan manipulado por los indiscriminados usos que se ha tenido de la palabra socialismo en el pasado siglo xx, en el que hasta Hitler se proclamó nacional socialista- como de las posibilidades de concreción del humanismo marxista.

Por suerte, la historia no ha muerto, y como sigue viva, seguirá experimentando nuevos proyectos sociales de superación de las sociedades contemporáneas. De otro modo habría que aceptar con tristeza la fatal eutanasia de la historia, la ideología, la ética, la política y la filosofía.

La muerte de la ideología y la filosofía ha sido proclamada por algunas interpretaciones simplificadoras, dentro del marxismo, de algunas ideas de Marx y Engels como la siguiente:

Las conclusiones a las que Marx nos permitió arribar remiten a nuestra inicial alusión acerca de la dependencia de la educación respecto

37 Norberto Bobbio, tal vez siguiendo a Rosa Luxemburgo sostenía "No puede haber socialismo donde no hay libertad". Bobbio, N. Las ideologías y el poder en crisis. Ariel. Barcelona. 1988. p. 66. y a la vez con honestidad reconocía "La igualdad del poder es una de las condiciones principales para el incremento de la libertad" p. 34. Esto significa que una sociedad que no asegura algunas posibilidades de realización de la igualdad o al menos la equidad difícilmente puede lograr la libertad. Esto lo reconoce abiertamente Bobbio al plantear que "socialismo, en todas sus diferentes y aun contrastantes encarnaciones, significa antes que nada una cosa: más igualdad" Idem. p. 33. 
de una concepción filosófica que no logra realizar sus presupuestos. Vimos también que dado el nexo inescindible entre filosofía y educación en la sociedad moderna, la liberación de la filosofía respecto de la ideología y la liberación de la educación respecto de su sometimiento a la falsa representación puede sobrevenir sólo a través de una filosofía auténticamente creadora: una filosofía que se disuelva en la transformación del mundo (Broccoli, 1978, p. 58).

El quid de la cuestión parece reducirse al logro de una filosofía "auténticamente creadora" que se inmole al generar ese "mundo nuevo" en el que la vida espiritual resultará tan aburrida sin ideologías ni filosofías.

La condición de materialista no se pone en entredicho porque se admita que las ideas por más que "reflejen" relaciones materiales, indiscutiblemente forman parte también de la realidad y hacen más complicado el asunto de determinar el carácter verdadero o falso de las formas ideológicas (Goldmann, 1979, pp. 98-99). ${ }^{38}$ De manera algo similar a las estructuras atómicas, el campo gravitacional, los procesos evolutivos biológicos, entre otros - que en el mundo material constituyen esa especie de "hiperrealidad" o "realidad ampliada" a la que se refiere David Alvargonzález (1966), en la que actúa y determina lo existente, aunque no lo percibamos- (p.22) $)^{39}$ las

38 Después de concluir que todo hecho social implica hechos de conciencia, cuyo rasgo estructural principal, es su adecuación a la realidad o no, Lucien Goldmann se cuestiona las razones del efecto diferenciado en la aceptación por la ideología nacionalsocialista en algunos sectores sociales alemanes al igual que la stalinista en los soviéticos y señala: "Hace falta saber además: a) lo que había de ilusorio o verídico en cada una de estas ideologías, y b) por qué tal o cual grupo social era víctima de estas ilusiones necesariamente o, al menos, con mayor facilidad. El problema se complica porque, siendo la conciencia a su vez un elemento de la realidad social, su existencia misma contribuye a que su contenido resulte adecuado o inadecuado". Goldmann, Lucien. Marxismo y ciencias humanas. Amorrortu, Editores. Buenos Aires. 1979. pp. 98-99.

39 "(...) la realidad ha de considerarse como un proceso in fieri dependiente en muchos de sus tramos, de la propia construcción de las verdades científicas. Así, va conformando una especie de "hiperrealidad" o una realidad "ampliada" que tiene en cuenta no sólo aquello que se aparece directamente a nuestros sentidos (las apariencias, los fenómenos) sino también aquello que actúa y determina lo existente, aunque no lo percibamos :las ondas electromagnéticas o gravitatorias, las estructuras atómicas, o los procesos evolutivos biológicos". Alvargonzález, David. "El darwinismo visto desde el punto de vista filosófico”, en El Basilisco. Oviedo. Enero-marzo. 1996. p. 22. 
formas ideológicas también forman parte de modo suigéneris de la realidad. De algún modo son percibidas, pero por sí mismas no determinan nada. Su participación en la determinación de lo existente siempre estará mediada por relaciones materiales, especialmente a través de la práctica de la política.

Las ideas, y entre ellas especialmente las filosóficas, tienen tanto derecho a ser objeto de análisis histórico como en distinto modo lo son las formas de relaciones de producción y de fuerzas productivas, aun cuando la especificidad de sus respectivos desenvolvimientos sea tan diferente.

Existe una relativa identidad natural entre el pensamiento y las condiciones de vida en que este se genera - como planteó Marx-, lo cual no le impidió a éste admitir la existencia de una historia de la teoría (Marx, 1975, p. 106 $)^{40}$ del valor como tantas otras historias de teorías e ideologías. Es indudable que se puede admitir con pleno valor científico la existencia de una historia de las ideologías, así como de las formas de enajenación, y demás, siempre y cuando se consideren lógicamente en su dialéctica articulación de determinación y relativa autonomía con las relaciones materiales.

Los componentes ideológico-políticos forman parte de la realidad, operan en ella y en ocasiones impulsan acciones tanto verdaderas como falsas, favorables como desfavorables al progreso humano.

Resulta plenamente aceptable la argumentación de Adam Schaff según la cual "Si alguien acepta la definición, por ejemplo, de que ideología significa lo mismo que falsa conciencia, entonces prejuzga ex definitione la disputa acerca de la objetividad de ciencia e ideología" (Schaff, 1980, p. 12). Es algo así como descalificar de la condición humana, y por tanto del uso de la razón, a nuestro oponente en una polémica filosófica.

Por ese intolerante camino se han conducido aquellos que han decidido aniquilar a quienes conciben como seres inferiores, incapaces de alcanzar

40 "Es cierto, por otra parte que la historia de la teoría demuestra -como usted supone con razón- que la concepción de la relación del valor siempre ha sido la misma, más o menos clara, a veces empañada de ilusiones, otras veces mejor definida científicamente. Como el proceso del pensamiento dimana de las condiciones de vida y es, de por sí, un proceso de la naturaleza, el pensamiento, en tanto aprehende realmente las cosas, no puede ser más que idéntico siempre y sólo puede diferenciarse gradualmente, de acuerdo con la madurez alcanzada por la evolución, y por ende también, con la madurez del órgano que sirve para pensar. Todo lo demás es puro disparate." Marx, Carlos. "Carta a Kugelmann". 11 de julio de 1868. Marx, C. Cartas a Kugelman. Editorial Ciencias Sociales. La Habana. 1975. p. 106. 
aquellas verdades únicamente comprensibles para privilegiados seres superiores considerados exclusivos usufructuarios de "la razón".

La toma de conciencia del componente ideológico en el discurso filosófico contemporáneo se convirtió en una preocupación de mayor envergadura después de la aparición del marxismo.

A pesar de que algunos filósofos de la encrucijada de las dos centurias pasadas intentaron cobijarse bajo el ideológico manto de la "neutralidad axiológica" weberiana, otros, con singular coraje como Nietzsche, no se han ruborizado al exponer sus proyecciones ideológicas.

El siglo xx trajo consigo una cristalización mayor de los conflictos ideológicos que irrumpieron en grandes guerras, revoluciones y contrarrevoluciones, y que impiden a cualquier filósofo que se autoestime pasar por alto tales acontecimientos. Nadie puede aislarse en aséptica cabina al margen de tan graves conflictos ideológicos que la humanidad ha decidido postergar para el siglo XxI, mientras algunos ilusos sueñan con "la muerte de las ideologías".

La toma de conciencia del lugar del componente ideológico en el ambiente filosófico, como en otras esferas de la vida cotidiana, se ha incrementado considerablemente, como se evidencia en las obras de Mannheim, Gramsci, Adorno, Marcuse, Althusser, entre otros, y en América Latina con Mariátegui, Silva, Sánchez Vázquez, Villoro, Zea, Roig, y otros.

En la misma medida, el pensamiento político contemporáneo sabe muy bien que las grandes batallas se deciden antes en las controvertidas esferas de las ideologías y en las múltiples realidades virtuales que generan constantemente los medios de comunicación masiva. La filosofía parece que tendrá mucho trabajo futuro desarticulando múltiples enigmas y efectos, y no solo ideológicos, de las cada vez más complejas manifestaciones de lo virtual.

Mientras que en el caso del pensamiento político la ideología constituye su eje principal y toda formulación está concebida en correspondencia con la misma, en la filosofía ella no opera de modo tan determinante, pues el fermento epistemológico pretende ser el protagónico. El componente ideológico está siempre presente en el discurso filosófico, pero su expresión discurre tras múltiples mediaciones, y en ocasiones, en algunas esferas de la reflexión filosófica resulta tan distante su efecto que apenas es perceptible, por lo que se pone en duda, no sin razón, su operacionalidad. 
Los gobernantes, por lo regular, expresan tener gran interés por la filosofía, como lo revela la atención que se le otorga en los sistemas educativos en distintos países, lo que con razón hace decir a Gustavo Bueno: "El papel de la filosofía académica en el conjunto del saber político de las sociedades democráticas tiene un sentido, sin duda, aún más directo cuando al saber filosófico se le considera en su universalidad virtual distributiva, "de derecho". Es un saber que debe ser distribuido, desde luego, como deber civil, universalmente, entre todos los ciudadanos, principalmente a través de la acción escolar (la misma acción a través de la cual se distribuye el saber aritmético elemental, o saber físico o el saber biológico elemental)" (Bueno, 1995, p. 101).

Por su parte, todo pensamiento político se articula en función de sustentar el poder efectivo de un sujeto social o intentar transformarlo. Con ese fin se apoya necesariamente en la fuerza racional que puede brindarle la filosofía, del mismo modo que se vale de la ciencia, la moral, el derecho, y hasta de la religión cuando le es necesario.

Aunque la filosofía puede ser acomodada en función de los intereses que se persiguen con su utilización, siempre porta en sí el irreverente instrumento de la razón, que puede convertirse en poderoso bumerán contra los argumentos de sus usufructuarios.

Las filosofías, cuando despliegan su actividad en el plano eminentemente lógico o epistemológico, no necesariamente se ven obligadas a incursionar en el mundo de las ideologías, pero a su vez no operan ideológicamente de manera efectiva si no se expresan de algún modo a través del pensamiento político. No todas las filosofías poseen en igual magnitud su componente ideológico, ni todas lo revelan de manera explícita. Sin embargo, todo pensamiento político sí muestra con agrado rápidamente su raigambre filosófica, sin considerarse tan comprometido a revelar su valor epistemológico. Gramsci (1966) era del criterio de que:

Un grupo social tiene su propia concepción del mundo aunque embrionaria, que se manifiesta en la acción, y que cuando irregular y ocasionalmente -es decir, cuando se mueve como un todo orgánico-, por razones de sumisión y subordinación intelectual, toma en préstamo una concepción que no es la suya, una concepción de otro grupo social, la afirma de palabra y cree seguirla, es porque la sigue en 


\begin{abstract}
"tiempos normales", es decir cuando la conducta no es independiente y autónoma sino precisamente sometida y subordinada. He aquí por qué no se puede separar la filosofía de la política, y por qué se puede demostrar, al contrario, que la elección de la concepción del mundo es también un acto político (p. 15).
\end{abstract}

En la antigüedad, el pensamiento político monárquico, aristocrático, democrático, entre otros, así como en la modernidad el liberalismo, el socialismo o el fascismo, siempre han contado con filósofos - considerados normalmente como sus ideólogos-, al servicio de gobernantes o aspirantes al poder. Sería iluso pensar que en la elaboración de sus propuestas teóricas, bien para mantener el poder o para alcanzarlo no hayan sido capaces de alcanzar resultados de real valor epistemológico, que fuera útil a las prácticas éticas y políticas de los diversos sujetos sociales.

Sin embargo, no todos los generadores de ideas filosóficas han ido conformando cada una de ellas en función de su proyecto político. Aunque el componente ideológico subyace en la integralidad de las concepciones de un filósofo, eso no significa que tiene que manifestarse en cada una de sus formulaciones aisladas.

Tanto la filosofía, como la ética, la ideología en general, y en especial la ideología política, son expresiones sui géneris de las relaciones materiales existentes en una época de la cual se toma conciencia y se pretende apuntalarlas o renovarlas. Por supuesto que dentro de estas múltiples relaciones las existentes entre las clases sociales resultan básicas, pero no son las únicas, y en ocasiones ni siquiera son las determinantes cuando se imponen criterios de género, generación, étnicos, religiosos, y demás.

Pero resulta ciertamente exagerado considerar que la filosofía es la lucha de clases en la teoría, como en una época pretendió Althusser, quien en ese momento de su marxismo estructuralista (Guadarrama, 2007, pp. 61-67) estableció un divorcio irreconciliable entre ideología y ciencia (Althusser, 1969, p. 178) - lo que por otra parte no debe empañar otras acertadas formulaciones suyas sobre el indisoluble nexo entre filosofía e ideología - , pues esto implica reducir de algún modo todo el rico universo del saber filosófico a uno de sus componentes, que con independencia de su importancia no es el exclusivamente determinante en su conformación. 
Althusser (1966) en un inicio concibió de forma maniquea la relación entre ciencia e ideología al plantear que:

\begin{abstract}
Una ideología es un sistema (dotado de su lógica y de reglas propias) de representaciones (imágenes, mitos, ideas o conceptos según los casos) provisto de una existencia y un papel histórico en el seno de una sociedad dada. Sin entrar en el problema de las relaciones entre una ciencia y su pasado (ideológico), digamos que la ideología como sistema de representaciones se distingue de la ciencia en que su función práctico-social predomina sobre su función teórica (o función de conocimiento) (p.224).
\end{abstract}

Tal acentuación de su función práctica, "inconsciente" (Althusser, 1966, pp. 225-226), "imaginaria" (pp. 225-226) ${ }^{42}$ y seudocientífica la mantuvo en trabajos posteriores en los que se consideraba autorizado a proponer una "teoría general de las ideologías," (Althusser, 1977, p. 102) hasta que se percató de las consecuencias que implicaba no admitir alguna posibilidad de fermento de objetividad, al menos en la ideología importada por la clase obrera con el marxismo.

41 "La ideología es profundamente inconsciente, incluso cuando se presenta (como es la filosofía "premarxista") bajo una forma reflejada. La ideología es un sistema de representaciones, que en la mayoría de los casos no tiene nada en común con la "conciencia": estas representaciones son, en la mayoría de los casos, imágenes y a veces concepto; pero es ante todo como estructuras que se imponen a la inmensa mayoría de los hombres, sin pasar por su "conciencia". Ellos son objetos culturales percibidos-aceptados-soportados, y actúan funcionalmente sobre los hombres mediante un proceso que estos no captan". Althusser, L. Por Marx. La Habana: 1966.Ediciones. Revolucionaria pp. 225-226.

42 "De hecho los hombres expresan en la ideología no sus relaciones con sus condiciones de existencia, sino la manera en que ellos viven su relación con sus condiciones de existencia lo que supone a la vez, relación real y relación "vivida", "imaginaria”. En consecuencia la ideología es la expresión de la relación de los hombres con su "mundo", es decir: la unidad superdeterminada de su relación imaginaria con sus condiciones de existencia reales. En la ideología la relación real está incluida inevitablemente dentro de la relación imaginaria: relación que sirve más para expresar una voluntad (conservadora, conformista, reformista o revolucionaria) e incluso una esperanza o una nostalgia, que para describir una realidad". p. 226. 
La tesis althusseriana de la filosofía como destacamento teórico de la ideología encontró también simpatías en Sánchez Vázquez (1982, p. VII). Esta formulación pareció no tomar en consideración que -al igual que su polo opuesto la desideologización (Sánchez y Guadarrama, 1998, pp. 92-108) - cualquier hiperbolización o extrapolación del lugar de lo ideológico en la filosofía afecta la adecuada comprensión de esta sui géneris forma de saber.

Para Adolfo Sánchez Vázquez (1987) "La filosofía solo podría ser inmune a la ideología si fuera totalmente científica" (p.63). De acuerdo con este criterio al menos existiría la posibilidad abstracta de una filosofía desideologizada. Y la historia cuenta en su haber con múltiples intentos de filosofías de equipararse al saber científico de algún modo, ya sea en Platón, Aristóteles, o en Hegel (1972). Al respecto este último planteaba:

La verdadera figura en que existe la verdad no puede ser sino el sistema científico de ella. Contribuir a que la filosofía se aproxime a la forma de la ciencia - a la meta en que pueda dejar de llamarse amor por el saber- para llegar a ser saber real: he ahí lo que yo me propongo. (p. 9).

También en los casos del positivismo, la fenomenología, la filosofía analítica, entre otras, que en algunas de sus modalidades han intentado inútilmente situarse - con la rara excepción del marxismo-por encima o al margen de las ideologías.

En estas corrientes filosóficas, en grado diferente, se ha apreciado la intención no solo de nutrirse de los avances de la ciencia, sino incluso hasta de ocupar el lugar de ella.

Independientemente del concepto que se maneje de la ciencia, todos los intentos de su equiparación han afrontado serias dificultades, al menos para que la comunidad científica internacional los acepte como tales. Tal vez ese criterio no sea razón suficiente para su exclusión. Pero lo cierto es que resulta más común que se otorgue validez científica a algunas de las formulaciones de estas filosofías que a la integralidad de su sistema teórico.

Ello significa que no han sido elaboradas al margen de los avances de las ciencias, pero de ahí a que sean consideradas propiamente una ciencia o que incluso lleguen a aspirar a autocalificarse como la única interpretación científica del mundo (Kuusinen, 1964, p. 9), hay un gran trecho. 
La filosofía constituye una forma específica del saber que exige no solo un desarrollo del pensamiento abstracto, sino también un grado de maduración del conocimiento científico (Bueno, 1987, p. 38), ${ }^{43}$ pero por su propia naturaleza ninguna filosofía llega a constituirse propiamente en una ciencia, a menos que a partir de ese momento abandone su condición de filosofía.

Otra cuestión es que en el seno de la filosofía se incube un conjunto de ideas que pueden paulatinamente incorporarse al dominio de la ciencia y también de la ideología, la moral y la política. Tan erróneo es establecer una absoluta dependencia entre la actividad del científico y sus criterios morales, como considerar que nada tiene que ver su condición de investigador y su postura ética o política, como pensaba Reichenbach (1975, p. 312). ${ }^{44}$ De lo contrario, no se entendería por qué Einstein se opuso a muchas de las investigaciones de algunos de sus colegas en Berlín sobre los efectos mortíferos de los gases de cloro o por qué después de Hiroshima y Nagasaki sintió profunda vergüenza con lo que se había derivado de sus investigaciones.

Una de las formas prejuiciadas de abordar las ideologías ha sido la de Schumpeter al considerarlas como "preconceptos" que escapan del control y se convierten en "peligrosas" (Schumpeter, 1968, p. 11) para la ciencia. Sostener que la condición de considerarse descontaminada de ideología constituye una premisa indispensable para lograr el carácter eminentemente científico, significa situar un obstáculo de exclusión insalvable entre lo científico y lo ideológico en el saber filosófico.

¿Qué razones impiden que una formulación filosófica, sin abandonar tal condición, posea elementos científicos y a la vez ideológicos?, ¿acaso no es posible que el saber filosófico sea lo suficientemente sagaz para

43 "Es un saber de segundo grado, porque supone la constitución histórica de categorías míticas, religiosas, técnicas, científicas, etc. La filosofía, pues, no nace con el hombre, no es connatural, sino un producto histórico cultural erigido sobre la base de múltiples saberes previos, sobre los cuales se ejerce la actividad crítica". Bueno, Gustavo. Hidalgo, Alberto y Carlos. Iglesias. Symploke. Ediciones Júcar. Barcelona. 1987. p. 38.

44 "Una filosofía científica no puede suministrar ninguna guía moral; ése es uno de sus resultados, y no es cosa que pueda oponérsele. ¿Queremos la verdad y nada más que la verdad? entonces no pidamos al filósofo directrices morales. Los filósofos prestos a derivar directrices morales de sus filosofías pueden ofrecer sólo remedos de prueba. Carece de sentido pedir lo imposible". Reichenbach, Hans. La filosofía científica. Fondo de Cultura Económica, México. 1975 p. 312. 
concordar con los avances de la ciencia en una determinada esfera, incluso sugerir ideas que contribuyan a su fundamentación y desarrollo, y a la vez se articule con una determinada postura ética e ideológica, bien sea la función del mantenimiento de un orden social existente o de su reforma o transformación revolucionaria?

El lugar del componente ideológico en el pensamiento político siempre ha sido y siempre será mucho más significativo que el que ocupa en el saber filosófico, con relativa independencia de los elementos científicos que estén contenidos en dicho pensamiento.

El contenido científico del pensamiento político se revela en mayor medida cuanto más carácter concreto posean sus formulaciones en relación con el poder estatal. El poder político, junto al económico y el ideológico, conforman el trípode básico de todo poder, en el que la moral aparentemente ocupa también una significativa función, pero en verdad resulta secundaria.

Aun cuando el poder económico constituya uno de los pilares fundamentales de todo poder, la creciente articulación entre el poder ideológico - que no resulta nada virtual, sino muy real si se concibe, como lo hace Helio Gallardo (1989) como "la capacidad de un grupo o clase o clases sociales para producir representaciones y valores socialmente legitimados" (p.63), entre los cuales se destacan lógicamente los valores éticos- , y el poder político desempeña en múltiples ocasiones la función detonante de muchas de las explosiones de la marcha histórica.

Los niveles de abstracción son imprescindibles en cualquier conocimiento científico siempre y cuando constituyan peldaños de profundización en lo concreto. Cuando la abstracción resulta vacía o débil de contenido, se da pie a la especulación, y de ese modo tanto la filosofía como el pensamiento político se ven afectados en su respectivo prestigio.

Aunque la existencia de elementos científicos en una ideología parezca un contrasentido, - pues tanto Pareto como otros tantos pensadores del siglo $\mathrm{xx}$ han caracterizado lo ideológico como la antítesis de lo científico-, en los últimos tiempos se ha hecho más común que se admita la posibilidad no solo de confluencia entre lo ideológico y lo científico, especialmente en lo referido 
al pensamiento político, sino que una ideología sociopolítica pueda ser científica, como reconoce también Mario Bunge (Bunge, 1985, pp. 131-132). ${ }^{45}$

La existencia de variados intentos de abordar científicamente la ideología y no solo desde el marxismo, como en el caso de la sociología del conocimiento de Karl Mannheim, es una prueba del interés humano por desentrañar todos los misterios, por fantasiosos que estos parezcan. Pero en este caso no se trata de un simple ejercicio intelectual de curiosidad, sino que consciente de la trascendencia práctica de la ideología en toda actividad humana, se aspira a conocer mejor sus mecanismos con sentido prospectivo.

Según Mannheim (1958, p. 113) existen dos visiones de la ideología: una particular, la marxista, aquella que deforma más o menos conscientemente la esencia de una situación, pues se dirige solo al contenido y al aspecto sicológico de los intereses; y otra general, la de la sociología del conocimiento, que considera la ideología de manera amplia, funcional y formal, pues revela las características de la estructura total del espíritu de una época o un grupo social, y aunque no investiga las causas sociales que condicionan las ideas, presta atención al contexto de acción donde operan.

Los argumentos ideológicos por sí mismos no pueden por naturaleza propia convertirse en elementos probatorios de veracidad, pero en determinadas circunstancias, no por el hecho de ser ideológicos, sino por el contenido real que tengan, pueden contribuir a la búsqueda de la verdad. En tal sentido, Luis Villoro coincide con Adolfo Sánchez Vázquez al considerar que "la ideología no forma parte del proceso de justificación del conocimiento, pero sí de las condiciones que lo enmarcan y hacen posible este proceso" (Villoro, 1985, p. 195).

"En verdad, lo que hace ideológico un planteamiento no es que esté o no suficientemente justificado — como asegura Villoro, quien admite que el

45 "En resolución, la construcción de ideologías sociopolíticas científicas es perfectamente posible. El que se las construya efectivamente es harina de otro costal. Marx y Engels intentaron elaborar una ideología científica a la que llamaron 'socialismo científico'. Pero sólo llegaron a la mitad del camino porque conservaron la dialéctica y gran parte del globalismo (holismo) de Hegel, y porque se aislaron de la 'ciencia burguesa' de su tiempo. Para peor, casi todos sus discípulos contribuyeron a momificar ese embrión de ideología científica. Al obrar de esta manera dogmática frustraron el intento de fusionar una ideología con la ciencia.”. Bunge, Mario. Seudociencia e ideología. Alianza. Universidad. Madrid. 1985. pp. 131-132. 
contenido de la ideología puede contener también elementos de verdad-, sino la función social que desempeñe al servir a un proyecto u otro, el cual puede estar o no suficientemente justificado".

Para Villoro (1982) "la ideología no es un pensamiento sin razones, sino un pensamiento con un razonamiento distorsionado por intereses particulares. El razonamiento ideológico suele fijar el proceso de justificación en argumentos y razones que no ponen en cuestión y que son susceptibles de ser reiterados una y otra vez" (p.122). Si el asunto fuese en realidad tan sencillo, las propuestas ideológicas nunca serían cuestionadas por los propios sostenedores de ellas. La base del componente ideológico no es siempre la creencia irracional, aunque en determinadas manifestaciones de lo ideológico pueda serlo, como resulta en el caso de las ideas religiosas o determinadas convicciones éticas y hasta jurídicas. Pero no siempre ocurre de esa manera en el caso de estas últimas y en otras expresiones de las formulaciones ideológicas. Así, el propio Villoro, después de ofrecer una definición de ideología, admite que "las creencias ideológicas tienen una justificación insuficiente, aunque no sean suficientemente falsas" (Villoro, 1982, p. 192), y adopta prejuiciadamente una actitud peyorativa ante lo ideológico al considerarlo de antemano "distorsionado por intereses particulares", sin antes ponerse previamente a verificar si son ciertos o falsos sus enunciados.

Para efectuar una crítica consecuente a cualquier planteamiento con carga ideológica, se supone idílicamente se parta de una postura de neutralidad axiológica y por tanto ética, la cual en realidad no ha existido ni existirá nunca. Por tanto, toda crítica a la significación de lo ideológico se efectúa desde una perspectiva ideológica, bien sea conocida o desconocida. Incluso en el hipotético caso de que seamos objeto de una valoración ejecutada por un extraterrestre, quien también portará sus perspectivas epistemológicas, así como fermentos éticos e ideológicos inexorablemente, al menos si es capaz de valorar en correspondencia con los intereses de la comunidad, ya sea de científicos, filósofos, políticos, u otros, a la cual pertenezca.

De lo que se trata, dado el reconocimiento de la imposibilidad del enfoque desideologizado, es de que el pensamiento político haga todo lo posible por que el componente ideológico no se superponga a la objetividad científica mínima requerida en cualquier análisis. El pensamiento político logrará siempre mayor credibilidad cuando sus formulaciones, más que acomodarse a evidentes preferencias ideológicas y éticas, sean capaces de plantear sus 
análisis con la mayor objetividad posible y prevalezca el rigor epistemológico por encima de intereses de cualquier índole. Tal actitud es la mejor postura ideológica a adoptar. Especialmente si se tiene en consideración que "en la ideología a diferencia de la ciencia lo fundamental no es conocer algo nuevo, sino usar un pensamiento para llegar a un fin concreto que satisface un interés (sea este de dominación o no)" (Iglesias, 1981, p.142.).

Si en los últimos tiempos sorprenden a muchos los triunfos electorales de partidos de derecha en determinados países, sin duda hay que buscar un conjunto de causas que los motivan. Pero entre ellas no se debe desestimar que los electores se frustran ante ciertos discursos utópicos abstractos de las izquierdas, que jamás pueden llegar a cumplimentarse, en tanto los experimentados ideólogos de las derechas apuestan en ocasiones con un discurso mucho más realista, por duro que sea, aunque siempre con el indispensable elemento demagógico.

Los pueblos del "socialismo real" se cansaron de esperar por la pletórica sociedad de consumo comunista que sus gobernantes les prometían a la vuelta de la esquina y optaron por una de consumo más realista, aunque lamentablemente fuese para una minoría. Todos se consideraron con posibilidades de entrar en ese reducido círculo de los privilegiados, aunque ahora la testaruda realidad les ha demostrado que también existe un capitalismo real, en lugar del idílico que les habían anunciado.

El fin de la centuria pasada y el inicio de la presente han estado cargados de espejismos que se han desvanecido con las mismas velocidades con que se han generado. Ni el propio Fukuyama se cree su muerte de la historia. Tampoco se produjo la anunciada desaparición de las ideologías, y ante la apariencia de debilitamiento de algunas, como es el caso de la conciencia tecnocrática, según Habermas (1992, pp. 96-97), ${ }^{46}$ a la vez se fortalece otro

46 "La conciencia tecnocrática es, por una parte, menos ideológica que todas las ideologías precedentes; pues no tiene el poder opaco de una ofuscación que sólo aparenta, sin llevar a efecto, una satisfacción de intereses. Pero por otra parte, la ideología de fondo, más bien vidriosa, dominante hoy que convierte en fetiche a la ciencia es más irresistible que las ideologías de viejo cuño, ya que con la eliminación de las cuestiones prácticas no solamente justifica el interés parcial de dominio de una determinada clase y reprime la necesidad parcial de emancipación por parte de otra clase, sino que afecta el interés emancipatorio como tal de la especie". Habermas, Jürgen. Ciencia como técnica y como ideología. Tecnos. Madrid. 1992. pp. 96-97. 
lado no menos ideológico que se deriva del mismo y aparente debilitamiento. En verdad, se está operando un proceso acelerado de nacimiento de nuevas ideologías que auguran una "tercera ola" en Turner con sociedades futuras cada vez menos homogéneas (Toffler, 1973, p. 335), ${ }^{47}$ o vaticinan el "choque de las civilizaciones" en Hungtinton, que no por ser eminentemente ideológicos dejan de tener a su vez valor epistemológico, pues necesitan apuntalarse en algunas verdades aunque sean muy relativas, para sustentar sus propuestas que nada tienen de relativas, sino una intención absoluta: acabar con todo lo que huela a socialismo.

Los que piensan que la clase obrera ha desaparecido y con ella arrastró a toda la estructura de clases, se levantan cada día atentos a los noticieros, preocupados ante los conflictos sociales que ya no pueden atribuir a los anarquistas o comunistas, pues estos se supone han desaparecido también de la historia. Ahora no saben a quién echarle la culpa por los motines de indignados en Madrid, Barcelona, Londres o Atenas, de emigrantes en múltiples ciudades norteamericanas, de víctimas del narcotráfico en México y Centroamérica o de estudiantes adolescentes en Santiago de Chile. La ceguera consciente de algunos de los nuevos ideólogos postmodernos hace revivir los calificativos de falseadores que Napoleón les atribuyó en su tiempo.

La práctica común de la política ha sido por regla general —como planteaba Holbach (1982) - la utilización del engaño, pues a juicio del materialista francés "seducida por intereses pasajeros en que cifra su grandeza y su poder, la política se cree obligada a engañar a los pueblos, a mantenerlos en sus prejuicios y a destruir en todos los corazones el deseo de la instrucción y el amor a la verdad" (p.50). Esta premisa no debe establecer la simple inferencia de que toda práctica de la política induce a la manipulación falseadora de las conciencias.

El pensamiento político ha sido más efectivo allí donde apoyado en el más avanzado conocimiento científico de la realidad que se propone transformar, en franca postura ideológica y con la adecuada fundamentación ética, revela los objetivos que persigue. En tales casos, la razonable argumentación

47 “(...) tendremos que avanzar hacia sociedades cada vez más diferenciadas. Esto provoca graves problemas de integración social.” Toffler, Arvin. El Schock del futuro. Plaza y Janes. Editores. Barcelona. 1973. p. 335. 
filosófica que fundamenta su actividad encuentra sus mejores fermentos generativos y sus más efectivos canales de comunicación.

En tanto se cultive esa orgánica articulación entre la dimensión epistemológica e ideológica, no habrá que temer a los efectos de esta última en la filosofía, en la ética, en la ciencia y mucho menos en el pensamiento político. Tanto la filosofía como la ética y la política tienen una permanente tarea futura en el perfeccionamiento humano. En esa multifacética labor la ideología no podrá en modo alguno seguir siendo toda la vida una rémora si se articula debidamente con las exigencias epistemológicas que presupone toda auténtica filosofía. 
Capítulo III 
